This item was submitted to Loughborough's Research Repository by the author.

Items in Figshare are protected by copyright, with all rights reserved, unless otherwise indicated.

\title{
High-entropy silicide ceramics developed from (TiZrNbMoW)Si2 formulation doped with aluminum
}

PLEASE CITE THE PUBLISHED VERSION

https://doi.org/10.1016/j.jeurceramsoc.2020.02.059

\section{PUBLISHER}

Elsevier BV

VERSION

AM (Accepted Manuscript)

\section{PUBLISHER STATEMENT}

This paper was accepted for publication in the journal Journal of the European Ceramic Society and the definitive published version is available at https://doi.org/10.1016/j.jeurceramsoc.2020.02.059.

\section{LICENCE}

CC BY-NC-ND 4.0

\section{REPOSITORY RECORD}

Qin, Yuan, Jin-Cheng Wang, Ji-Xuan Liu, Xiao-Feng Wei, Fei Li, Guo-Jun Zhang, Chengxi Jing, Jiawei Zhao, and Houzheng Wu. 2020. "High-entropy Silicide Ceramics Developed from (tizrnbmow)si2 Formulation Doped with Aluminum”. Loughborough University. https://hdl.handle.net/2134/11929830.v1. 


\title{
High-entropy silicide ceramics developed from (TiZrNbMoW)Si formulation doped with aluminum
}

Yuan Qin ${ }^{1,2}$, Jin-Cheng Wang ${ }^{1, *}$, Ji-Xuan Liu $^{2}$, Xiao-Feng Wei ${ }^{2}$, Fei Li ${ }^{2}$, Guo-Jun Zhang ${ }^{2, *}$, Chengxi Jing ${ }^{3}$, Jiawei $\mathrm{Zhao}^{3}$ and Houzheng $\mathrm{Wu}^{3, *}$

1. College of Chemistry and Chemical Engineering, Shanghai University of Engineering Science, Shanghai, 201620, China

2. State Key Laboratory for Modification of Chemical Fibers and Polymer Materials, Institute of Functional Materials, College of Materials Science and Engineering, Donghua University, Shanghai 201620, China

3. Department of Materials, Loughborough University, Leicestershire LE11 3TU, United Kingdom

*Correspondence: wjc406@sues.edu.cn, gjzhang@dhu.edu.cn, h.wu2@1boro.ac.uk

\begin{abstract}
We report a success in synthesizing high entropy silicides (HES) compounds and manufacturing well-densified HES ceramics through spark plasma sintering. For a designed chemical formula as $\left(\mathrm{Ti}_{0.2} \mathrm{Zr}_{0.2} \mathrm{Nb}_{0.2} \mathrm{Mo}_{0.2} \mathrm{~W}_{0.2}\right) \mathrm{Si}_{2}$, the as-synthesized HES showed a formula as $\left(\mathrm{Ti}_{0.22} \mathrm{Zr}_{0.06} \mathrm{Nb}_{0.29} \mathrm{Mo}_{0.22} \mathrm{~W}_{0.21}\right) \mathrm{Si}_{2}$ with zirconium partially oxidized into zirconia. Doping with aluminum resulted in a HES with the same composition, promoted formation of $\mathrm{ZrSi}_{2}$ and $\mathrm{Al}_{2} \mathrm{O}_{3}$. XRD analysis of as-synthesized HES is well supported by the calculated diffraction data based on a $2 \times 3 \times 1$ supercell with HCP crystal structure and experimental chemical composition. The cations in this HES crystal structure can occupy their positions randomly with little change of its lattice parameters and formation enthalpy.
\end{abstract}

Keywords: high-entropy silicide (HES), crystal structure of HES, supercell, zirconium, aluminum 


\section{Introduction}

High-entropy alloys (HEAs), deemed to consist of equimolar or approximately equimolar (e.g. between 5-35 mol\% for a single element) of five or more metal elements with simple facecentered cubic (FCC), body-centered cubic (BCC) or hexagonal closest packed (HCP) crystal structures, have attracted researcher's attention because of their promising better performance in wear resistance, strength from room to elevated temperatures, and corrosion and neutron irradiation resistance [1-4]. Recently, the high-entropy concept has been successfully applied to compounds with covalent/ionic bonds. Hence, high-entropy ceramics (HECs) have been actively explored, including high-entropy oxides [5-10], high-entropy carbides [11-16], highentropy diborides [17-20], and entropy-stabilized metal oxycarbonitride [21].

Very recently, we reported a preliminary success in synthesizing high-entropy silicide (HES) with a designed chemical formula as $\left(\mathrm{Ti}_{0.2} \mathrm{Zr}_{0.2} \mathrm{Nb}_{0.2} \mathrm{Mo}_{0.2} \mathrm{~W}_{0.2}\right) \mathrm{Si}_{2}$ [22]. The rationale for selecting this composition was based on an intention of developing silicide compounds composed of atoms in group 4 to 6 with relatively smaller neutron absorption cross section, which may provide potential for application in nuclear fuels. In this composition, the five metallic elements were a mixture of those from the three groups: Ti and $\mathrm{Zr}$ from group-IV with $\mathrm{Hf}$ excluded due to its very high neutron absorption cross section; $\mathrm{Nb}$ from group- $\mathrm{V}$ with $\mathrm{V}$ and Ta excluded due to toxic consideration of its oxides and high vapour pressure at high temperatures respectively; $\mathrm{Mo}$ and $\mathrm{W}$ from group-VI with $\mathrm{Cr}$ excluded due to less environmentally friendly of hexavalent chromium in its compounds.

The study published in [22] showed that a HCP crystal structure was evidenced by X-ray powder diffraction spectrum, and fairly uniform distribution of chemical elements by SEMEDS maps. It was noted, however, that (a) the XRD analysis had little support as no data available in any existing databases; (b) zirconium element was significantly deficient in the assynthesized HES formula. At that time, it was believed that the oxidation of zirconium may have been responsible for the $\mathrm{Zr}$ deficiency because zirconium oxide particles were widely probed in the as-manufactured samples [22]. This oxygen impurity may have come from the starting metallic powders where surface oxides were unavoidable due to storing and treatment in air. Oxygen contamination may also happen during powder processing, as widely noted in manufacturing non-oxide ceramics [23-25].

Along with our work, Gild et al reported similar investigation showing the success in synthesising a HCP HES with a designed formulation as $\left(\mathrm{Ti}_{0.2} \mathrm{Nb}_{0.2} \mathrm{Mo}_{0.2} \mathrm{Ta}_{0.2} \mathrm{~W}_{0.2}\right) \mathrm{Si}_{2}$ [26]. In the work reported in [26], it seems that all metal elements had participated in HES development, 
and no clear deficiency of any elements was measured. However, they did claim a significant amount of silica and possible titanium oxide developed in the as-manufactured samples, which was not explain how these oxides were formed. In comparison with our past/actual work, it is speculated that zirconium might be one of those elements that is difficult to participate the HES development under the synthesising conditions used. In order to clarify if zirconium would be less favoured for the HES development, the first necessary step is to reduce and even eliminate the oxidation of zirconium.

Different existing forms of oxygen could result in different microstructures and then properties of as-prepared polycrystal non-oxide ceramics. Oxygen as impurity in non-oxide ceramics can form secondary crystals or glassy interfacial phases with other elements [27], and in some cases, can dissolve into the primary phase to form a solid solution [28, 29]. For example, in $\mathrm{Si}_{3} \mathrm{~N}_{4}$ ceramics, the dissolving of oxygen into crystal can significantly reduce the thermal conductivity of $\mathrm{Si}_{3} \mathrm{~N}_{4}$ [29]. In $\mathrm{ZrB}_{2}$ ceramics, oxygen impurity on the grain boundaries makes high temperature strength deteriorated rapidly as temperature raises [25, 30, 31]. It was also noted that impurity oxide scale on the surface of $\mathrm{ZrB}_{2}$ particles decreases the surface energy, leading to obstructing densification behaviour [32].

To have a further understanding of the HES developed in $\left(\mathrm{Ti}_{0.2} \mathrm{Zr}_{0.2} \mathrm{Nb}_{0.2} \mathrm{Mo}_{0.2} \mathrm{~W}_{0.2}\right) \mathrm{Si}_{2}$, we re-designed the formulation with aluminium doping to purge most of possible oxygen involved in the synthesis process. The study reported here will demonstrate: (a) that a well densified HES ceramic can be achieved with the new formulation; (b) that a same formula high-entropy compound is achieved when zirconium is not oxidized. In addition, as per experimental data, we will validate the crystal structure of the as-developed HES with the support of DFT calculation and calculated XRD data.

\section{Experimental procedures}

As per definition of high entropy alloys, a high-entropy silicide, called HES-Al, with a base formula as $\left(\mathrm{Ti}_{0.2} \mathrm{Zr}_{0.2} \mathrm{Nb}_{0.2} \mathrm{Mo}_{0.2} \mathrm{~W}_{0.2}\right) \mathrm{Si}_{2}$ used in previous work [22], was designed to have 3 $\mathrm{wt} \%$ aluminium powder doped in the mixture of raw materials, followed by synthesis and densification through SPS sintering. The addition of $3 \mathrm{wt} \%$ aluminium was based on $(a)$ the measurement of $\mathrm{O}$ content of $\sim 1.5 \mathrm{wt} \%$ in an as-manufactured HES without aluminium doping, which theoretically needs $\sim 2 \mathrm{wt} \% \mathrm{Al}$ to scavenge it; (b) Al power itself is likely oxidized during storing and treatment, which leads to $50 \%$ extra $\mathrm{Al}$ added in the formulation. For comparative 
study, a high entropy silicide of (TiZrNbMoW)Si $i_{2}$ without aluminium doping, called HES, was prepared at the same time in the same batch. Details on processing and synthesis of highentropy silicide have been presented in a previous paper [22], and an outline is given here.

Details on each raw material are summarised in Table I, including the claimed levels of chemical purity and average particle sizes (D50) by suppliers.

\section{Table 1}

Summary of raw materials used.

\begin{tabular}{|c|c|c|c|}
\hline Powder & $\begin{array}{l}\text { purity } \\
(\mathrm{wt} \%)\end{array}$ & $\begin{array}{l}\text { Particle size } \\
(\mathrm{D} 50)(\mu \mathrm{m})\end{array}$ & Supplier \\
\hline $\mathrm{Ti}$ & 99.6 & 45 & Shaanxi Fengxiang Titanium Powder Co. Ltd., China \\
\hline $\mathrm{Zr}$ & 99.9 & 45 & $\begin{array}{l}\text { Beijing Zhongjinyan New Material Technology Co. Ltd., } \\
\text { China }\end{array}$ \\
\hline $\mathrm{Nb}$ & 99.9 & 45 & $\begin{array}{l}\text { Shanghai Aladdin Biochemical Technology Co. Ltd., } \\
\text { China }\end{array}$ \\
\hline $\mathrm{W}$ & 99.6 & 0.8 & China New Metal Materials Technology Co. Ltd., China \\
\hline Mo & 99.6 & 45 & China New Metal Materials Technology Co. Ltd., China \\
\hline $\mathrm{Si}$ & 99.6 & 45 & Jinan Yinfeng Silicon Products Co. Ltd., China \\
\hline $\mathrm{Al}$ & 98.0 & 3 & Huabang Powder Materials Co. Ltd., China \\
\hline
\end{tabular}

The mixtures of the starting powders were ball-milled for 10 hours with silicon nitride ball as grinding medium and ethanol as solvent. The weight ratio of powders to grinding medium was 1:3, and no weight change of silicon nitride balls was measured after ball-milling. The asdried powder mixtures were filled in a graphite die with a cavity of $10 \mathrm{~mm}$ in diameter, followed by synthesis and sintering inside a SPS furnace (FCT, KCE®-FCT H-HP D 25, Germany). Base on previous experience [22], $1300{ }^{\circ} \mathrm{C}$ was chosen as the final synthesis/sintering temperature. Temperature ramp rate was set as $100{ }^{\circ} \mathrm{C} / \mathrm{min}$; pressure applied on powder compact was $30 \mathrm{MPa}$; dwelling time at $1300{ }^{\circ} \mathrm{C}$ was 15 minutes. The cooling rate was not controlled after turning off the power at the end of dwelling. The diameter and thickness of as-manufactured samples are $\sim 10 \mathrm{~mm}$ and $\sim 5 \mathrm{~mm}$ respectively. Archimedes' method was used to measure the density of as-prepared samples.

For characterisation, samples were mounted in resin, followed by grinding and polishing to obtain a surface finish with $1 \mu \mathrm{m}$ diamond grits by using a LabForce-100 polishing machine (Struers, UK). Vickers hardness was measured with a microindenter (FV-700, FUTURETECH Co. Ltd., Japan) by using an indentation load of $1 \mathrm{~kg}$ with a dwell time of $5 \mathrm{~s} .10$ measurements were done to give an averaged hardness.

Phase composition and structure in the as-sintered materials were investigated by using Xray diffractometer (Bruker D8, Bruker Corporation, Karlsruhe, Germany) with $\mathrm{Cu} \mathrm{K}_{\alpha}$ radiation 
employed under a voltage of $40 \mathrm{kV}$. In order to calibrate diffraction peak positions when XRD data was processed, a mixture of lanthanum hexaboride (LaB6) in methanol was sprinkled on the sample surface where scattered X-rays were acquired. After drying, a very thin layer of $\mathrm{LaB}_{6}$ was remained on the sample surface. The scanning range of X-ray diffraction was 20 to $100^{\circ}$ with a step size $0.01^{\circ}$ and scanning time $0.5 \mathrm{~s} / \mathrm{step}$. All XRD patterns were processed using Diffract.eva.

The microstructure and chemical elemental distribution of the samples were characterized using field emission gun scanning electron microscopy (JEOL 7800F, Japan and TESCAN MA/A 3, Czech Republic) and energy dispersive X-ray spectrometer (DES, Oxford Instruments plc, UK). High probe current and high accelerating voltage of $20 \mathrm{kV}$ were used under backscattered electron mode. Element mapping was collected under a magnification of $\times 1000$ times. After mapping, the spectra from the regions of interest were reconstructed to estimate the chemical compositions.

Commercial software package (HSC Chemistry 6.1) was used to perform the thermodynamic calculations. Density functional theory calculations were conducted with Quantum Espresso [33][34]. Perdew-Burke-Ernzerhof generalized gradient approximation (PBE GGA) functional [35] and ultrasoft pseudopotentials provided by Quantum Espresso were used. Kinetic-energy cut-off and charge density cut-off are set as 50Ry and 700Ry respectively. A $0.4 \mathrm{~A}^{-1}$ Monkhorst-Pack k-point mesh and smearing of $0.02 \mathrm{Ry}$ were implemented. The convergence threshold for self-consistent field (SCF) calculation is $1.0 \times 10^{-}$

${ }^{7}$ Ry. A special quasirandom structure (SQS) was created by Alloy-Theoretic Automated Toolkit (ATAT) with lattice vector $\vec{a}=(2,0,0), \vec{b}=(0,3,0)$ and $\vec{c}=(0,0,1) .18$ metal atoms and 36 silicon atoms were included in the generated supercell [36][37]. For validation, additional 4 different structures with same size of SQS structure were randomly generated. All 5 structures were fully relaxed. The cell parameters (a and c) and energy were calculated after relaxation. Theoretical XRD patterns were calculated for comparing to experimental ones. Xcrysden and VESTA were used during visualization and XRD pattern calculation [38][39].

\section{Results and discussion}

\subsection{Microstructure}

The average density of the as-sintered compacts with aluminium doping was $6.03 \mathrm{~g} / \mathrm{cm}^{3}$, slightly lower that that without $\mathrm{Al}$, which was $6.22 \mathrm{~g} / \mathrm{cm}^{3}$ [22]. The densification of the 
polycrystal compacts was analysed by SEM images taken from as-polished and as-fractured surfaces. Representative images are displayed in Fig. 1. It is noted that only isolated pores exist in regions associated with the secondary phases with typical sizes smaller than $\sim 2 \mu \mathrm{m}$ and area fraction $<1 \%$, as shown in Fig. 1a. It is highly likely that some of these pores were caused by surface polishing, because no such pores are seen on the as-fractured surface as shown in Figure 1(c). The as-sintered ceramics are therefore deemed as nearly fully densified under the chosen processing and sintering conditions.
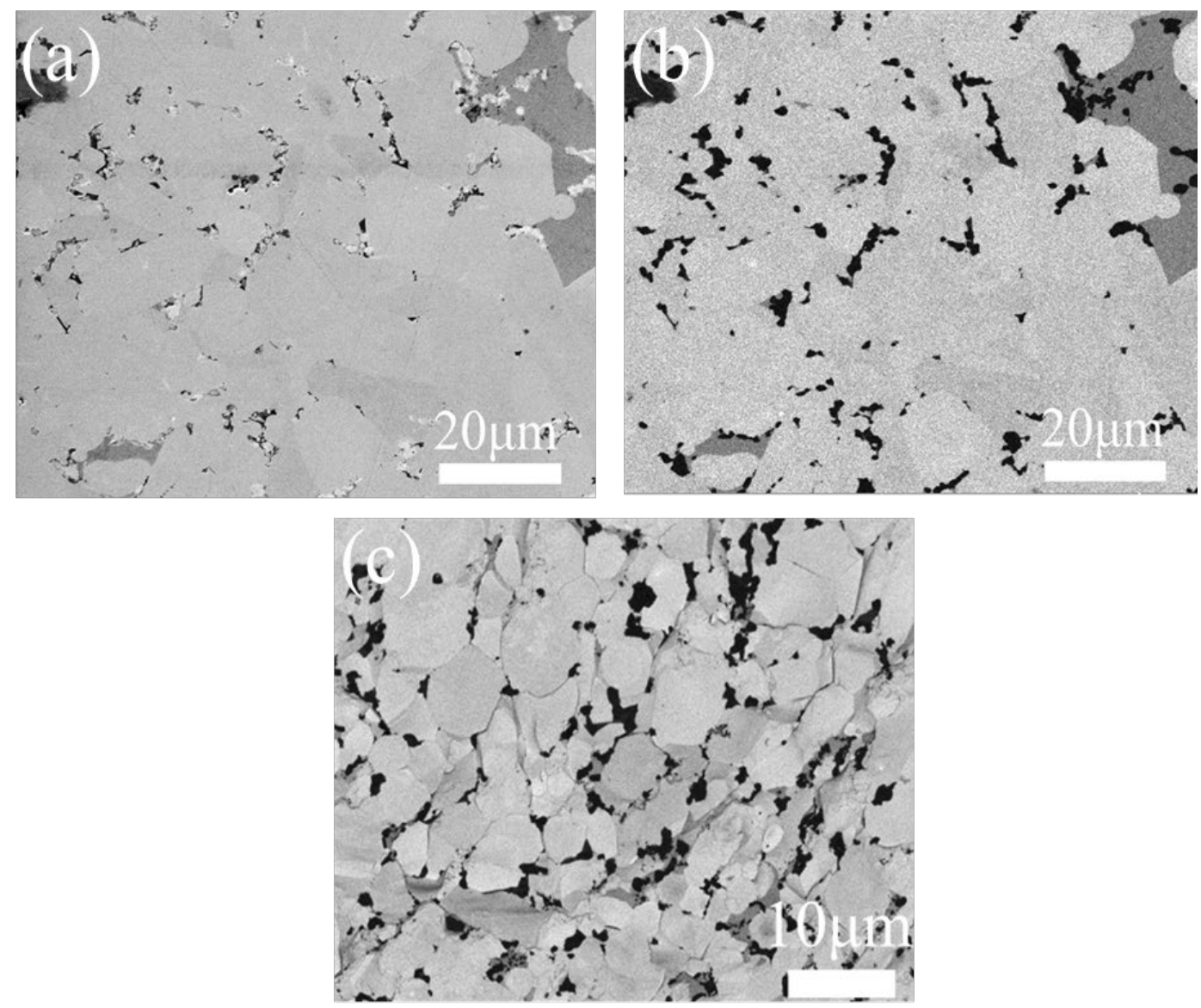

Fig. 1. SEM images of as-sintered HES with Al doping, contrasted with (a) secondary and (b) back scatted electrons, showing the HES regions with heavier chemical element distributed homogeneously and patched darker regions enriched with relatively lighter chemical elements; (c) back scatted electrons image of as-fracture surface of HES-Al, showing the grain structure of HES as primary phase in grey contrast, dispersed particles as secondary phase in dark contrast, and no visible pores. Small pores seen in (a) are likely artificial generated by surface polishing. 
When the SEM image was acquired using back scattered electrons as shown in Fig. 1b, most area shows a homogeneous pale contrast, evidencing that chemical elements in this area are heavier than those showing darker contrast, and their distribution is homogeneous. Some patched small regions show darker contrast, implying lighter chemical elements enrichment. To reveal more details of chemical element distribution, EDS mapping results are given later.

Fig. 1c shows the as-fractured surface of the as-sintered ceramic. The fracture is mostly transgranular with grain structure exposed clearly. The grain sizes are estimated to be around $\sim 4$ to $\sim 10 \mu \mathrm{m}$ for the primary HES phase, and 1-4 $\mu \mathrm{m}$ for most of the secondary-phase regions. Almost all particles of the secondary phase were on the grain boundaries with few inside the grains of primary phase.

\subsection{Chemical element distribution and composition}

The representative chemical element maps are presented in Fig. 2b-i for a region illustrated in Fig. 2a, showing the distribution of $\mathrm{Ti}, \mathrm{Zr}, \mathrm{Nb}, \mathrm{Mo}, \mathrm{W}, \mathrm{Si}, \mathrm{Al}$ and $\mathrm{O}$ respectively. The key characteristics are summarized here:

(a) The majority of the mapped region shows homogeneously distributed element $\mathrm{Ti}, \mathrm{Zr}, \mathrm{Nb}$, Mo, $\mathrm{W}$ and $\mathrm{Si}$, whilst the intensity of $\mathrm{Zr}$ is much lower than that of any other elements. This region is the primary phase, i.e. a well-developed HES. This HES region corresponds to the areas in the SEM images showing pale contrast due to higher electron yields of the heavier atoms. Quantification of EDS data acquired from this region gives a chemical formula as $\left(\mathrm{Ti}_{0.22} \mathrm{Zr}_{0.06} \mathrm{Nb}_{0.29} \mathrm{Mo}_{0.22} \mathrm{~W}_{0.21}\right) \mathrm{Si}_{2}$ as listed in Table 2. Note, in this quantitation, no atomic number effect, self-absorption effect and fluorescence effect are accounted to correct the X-ray intensities that are likely modified by the composition of the specimen. Given the high weight of the cations considered, minimal error is encountered during quantification by SEM-EDS.

(b) It is noted that $\mathrm{Al}$ and $\mathrm{O}$ are homogeneously scattered thorughout the microstructure and placed in the same locations, suggesting the formation of $\mathrm{Al}_{2} \mathrm{O}_{3}$ particles, as shown in Fig. 2h-i. Quantitative analysis of EDS acquired from these regions shows that the chemical formula of Al- and $\mathrm{O}$-enriched region is indeed close to $\mathrm{Al}_{2} \mathrm{O}_{3}$. It is noted that the size of $\mathrm{Al}_{2} \mathrm{O}_{3}$ particles is $<4 \mu \mathrm{m}$, and most of them sit on the boundaries though some inside the crystal grains, which rightly corresponding to the average size of Al powder used. Image analysis shows the area fraction of $\mathrm{Al}_{2} \mathrm{O}_{3}$ is about $5.19 \pm 0.16$ area\%. 
(c) Quite large patches with $\mathrm{Zr}$ enrichment are noted and shown in Fig. 2c. In these regions, there is a clear deficiency of $\mathrm{Ti}, \mathrm{Nb}, \mathrm{Mo}, \mathrm{W}$, but not for $\mathrm{Si}$, indicating that these regions must be composed of $\mathrm{Zr}$ and Si. Quantitative analysis of EDS acquired from these regions indicates that their chemical formula is close to $\mathrm{ZrSi}_{2}$, as listed in Table 2 called secondary phase. Image analysis shows the area fraction of $\mathrm{ZrSi}_{2}$ is about $4.81 \pm 0.27 \mathrm{area} \%$. It is noted some $\mathrm{Al}_{2} \mathrm{O}_{3}$ particles are also included in these regions.

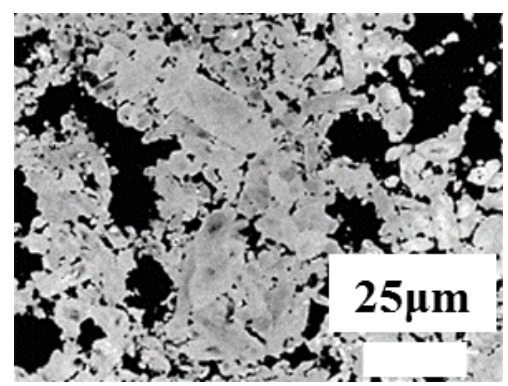

(a)

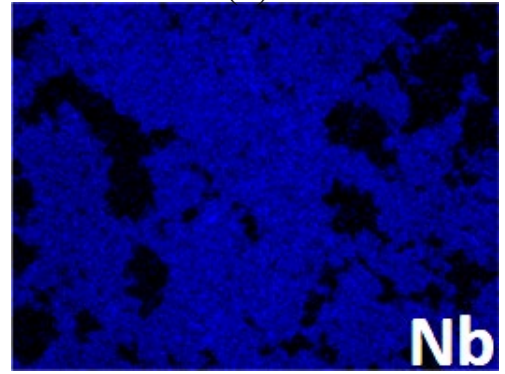

(d)

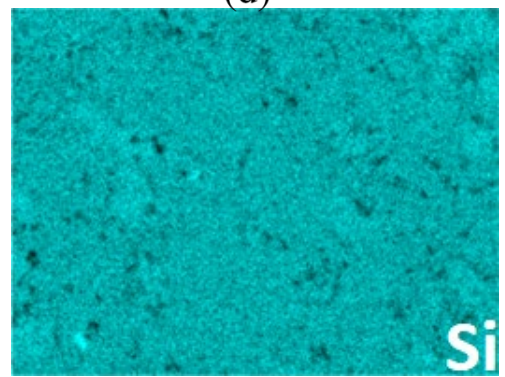

(g)

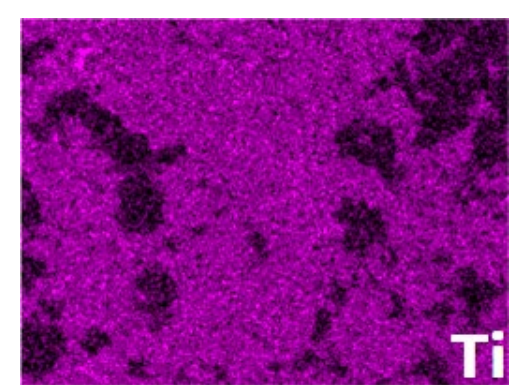

(b)

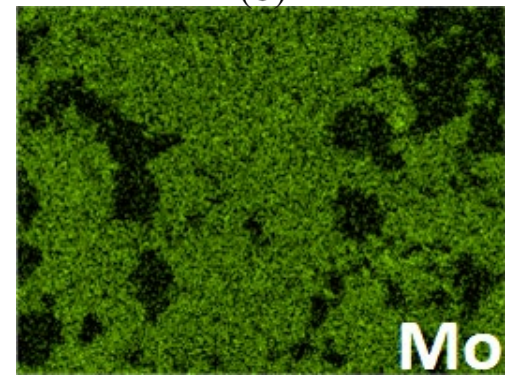

(e)

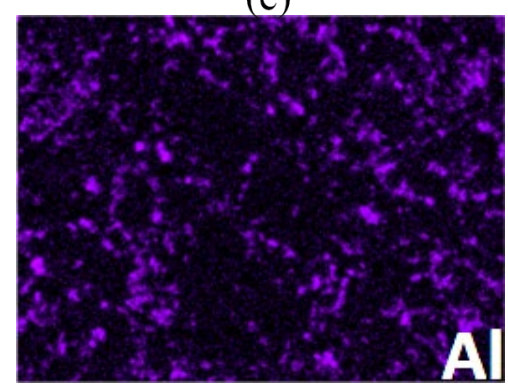

(h)

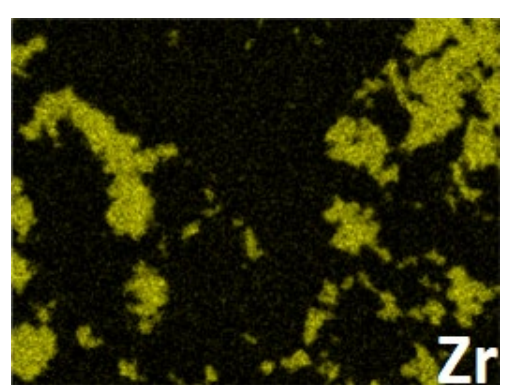

(c)

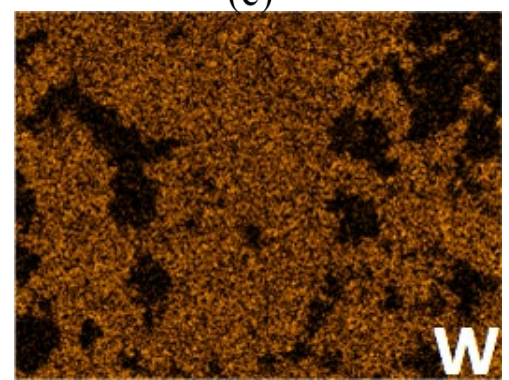

(f)

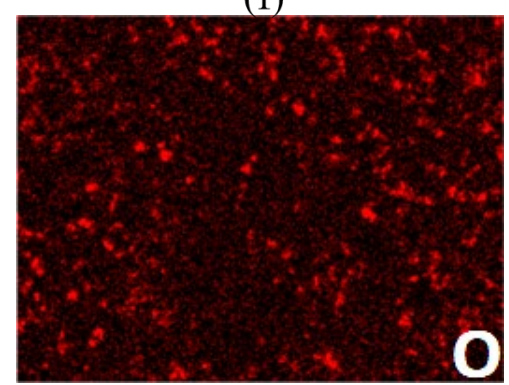

(i)

Fig. 2. Representative microstructure and chemical element maps of as-sintered (TiZrNbMoW)Si $i_{2}$ with Al doping: (a) SEM image, and (b-i) element map of Ti, Zr, Nb, Mo, $\mathrm{W}, \mathrm{Si}, \mathrm{Al}$ and $\mathrm{O}$ respectively.

Through the chemical element mapping, we have seen that with the doping of $\mathrm{Al}$ in the HES formulation, no more $\mathrm{ZrO}_{2}$ were detected, which was the original aim for the formulation with aluminium doping. However, only $\sim 1 / 3$ of $\mathrm{Zr}$ in the designed formulation participated the development of HES phase, which is the similar level as the HES produced without Al. Therefore, preferential oxidation of $\mathrm{Zr}$ is not the main reason for $\mathrm{Zr}$ exclusion from the HES 
phase, as supposed in [22]. Instead, most of the unoxidized $\mathrm{Zr}$ reacted with $\mathrm{Si}$, leading to the formation of a stable $\mathrm{ZrSi}_{2}$ binary compound, which was not observed in the Al-free HES where part of excluded $\mathrm{Zr}$ bonded with $\mathrm{O}$ to form $\mathrm{ZrO}_{2}$, as evidenced by XRD data shown in Fig. 3 (More analysis of the spectra is included in section 3.3). Hence, an open question is raised here: is $\mathrm{Zr}$ energetically not favoured to participate the HES development under current manufacturing conditions? By now, there is no answer for this question, and further understanding is needed.

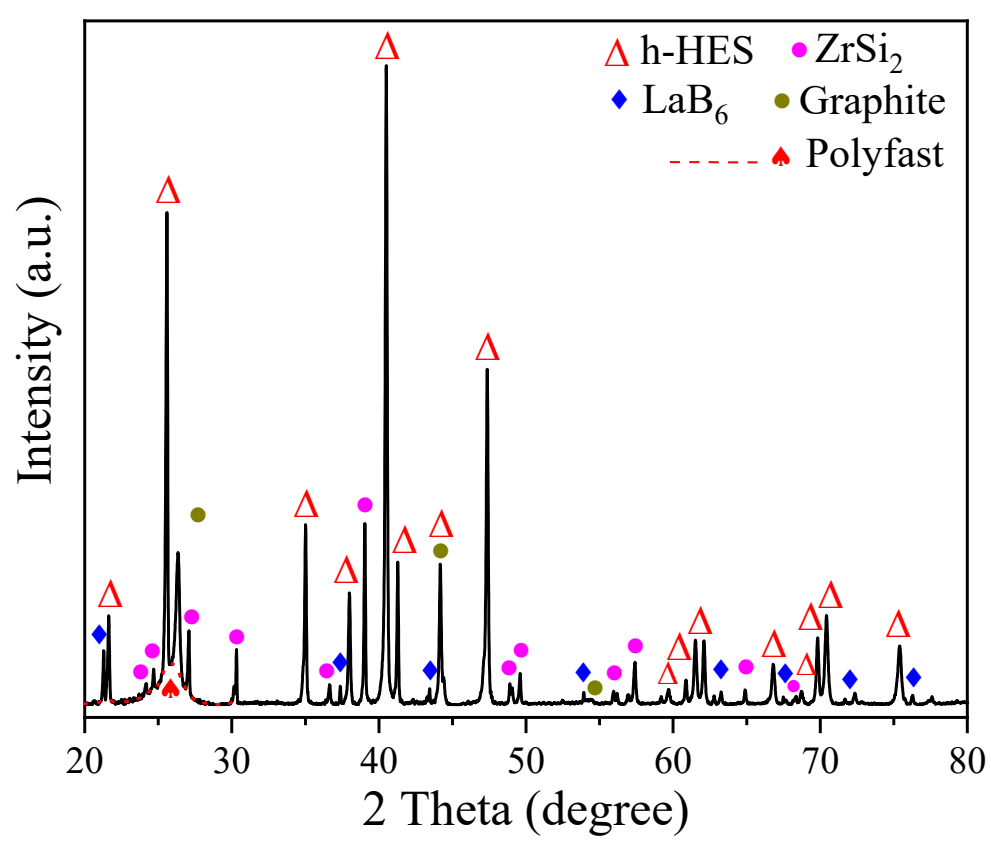

(a)

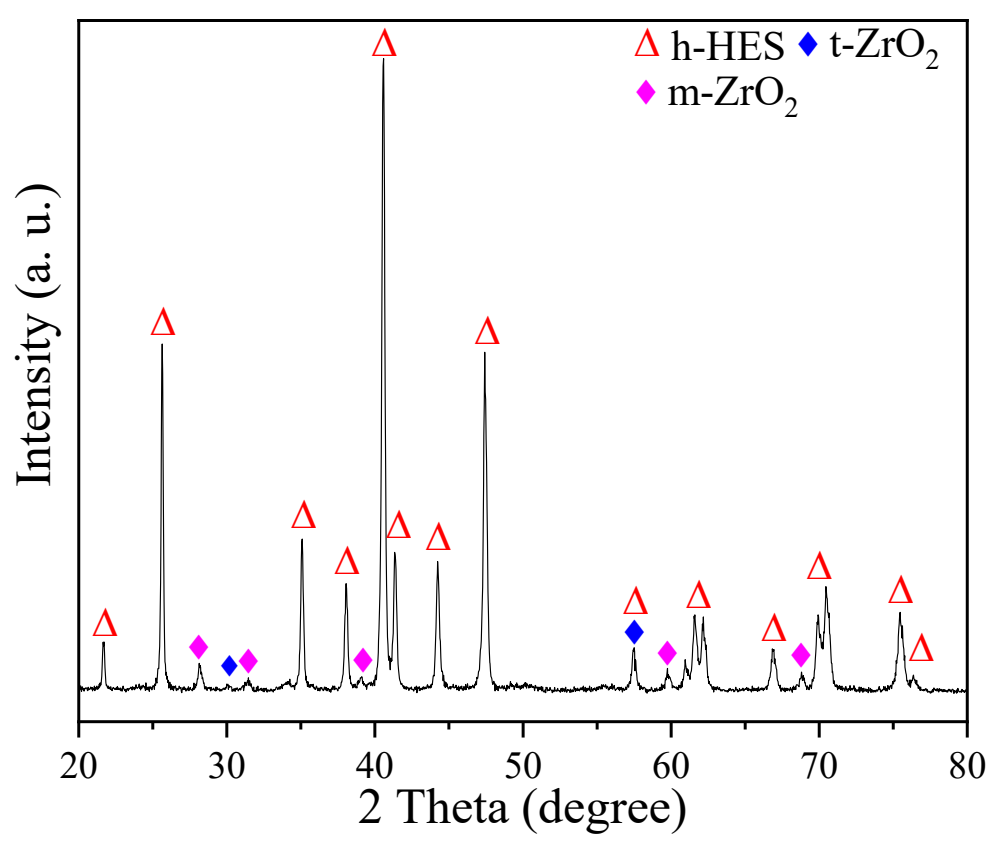


(b)

Fig. 3. X-ray diffraction spectrum acquired from an as-polished surface of an HES (a) with Al doping and (b) without Al-doping. In (a), HES and $\mathrm{ZrSi}_{2}$ represent the primary and secondary phase. $\mathrm{LaB}_{6}$ diffraction peaks are from sprinkle $\mathrm{LaB}_{6}$ powder on the surface used for peak position calibration. Diffraction peaks of graphite and phenolic resin (also called polyfast) are from the sample mounting resin. In (b), the primary and secondary phase are HES and $\mathrm{ZrO}_{2}$ respectively.

That said, $\sim 6 \mathrm{~mol} \%$ of $\mathrm{Zr}$ incorporated in HES cannot be treated as negligible. Following the general consense on chemical element content in a high entropy alloy or compound, the fraction of a single chemical element could vary from 5 to $35 \mathrm{~mol} \%$ [1], meaning that the 6 mol\% in the as-synthesized HES is still within a sensible range. On the other hand, the exclusion of a chemical element in a high-entropy compound is not unusual. We have noted that $\mathrm{Zr}$ and $\mathrm{Nb}$ had inhomogeneous distribution in an as-synthesized high entropy carbide $\left(\mathrm{Ti}_{0.2} \mathrm{Zr}_{0.2} \mathrm{Nb}_{0.2} \mathrm{Ta}_{0.2} \mathrm{~W}_{0.2}\right) \mathrm{C}[15]$ but a single phase was evidenced by $\mathrm{X}$-ray diffraction spectrum.

Table 2

Chemical compositions from quantification of EDS data in the primary and secondary regions in the as manufactured polycrystal compacts.

\begin{tabular}{|c|c|c|c|c|c|c|c|c|c|}
\hline \multirow{2}{*}{ Region } & & \multicolumn{8}{|c|}{ Chemical elements in $\mathrm{mol} \%$} \\
\hline & & $\mathrm{Ti}$ & $\mathrm{Zr}$ & $\mathrm{Nb}$ & Mo & W & $\mathrm{Si}$ & $\mathrm{Al}$ & $\mathrm{O}$ \\
\hline \multirow[t]{2}{*}{ Primary } & Average & 6.6 & 2.0 & 9.0 & 6.8 & 6.1 & 63.7 & 2.1 & 3.8 \\
\hline & $\begin{array}{l}\text { Standard } \\
\text { deviation }\end{array}$ & 0.4 & 0.4 & 1.8 & 1.1 & 0.9 & 3.4 & 2.1 & 2.3 \\
\hline \multirow[t]{2}{*}{ Secondary } & Average & 1.5 & 26.5 & 0 & 0.3 & 0.4 & 59.7 & 3.4 & 8.2 \\
\hline & $\begin{array}{l}\text { Standard } \\
\text { deviation }\end{array}$ & 0.1 & 2.2 & 0.1 & 0.1 & 0.2 & 4.2 & 1.6 & 4.4 \\
\hline
\end{tabular}

The relatively small sizes of $\mathrm{Al}_{2} \mathrm{O}_{3}$ regions and their distribution along the grain boundaries induce to speculate that the oxidation of Al may have happened at relatively lower temperatures and/or before silicides started to be developed. The size of $\mathrm{Al}_{2} \mathrm{O}_{3}$ regions is just equivalent to that $(\sim 4 \mu \mathrm{m})$ of $\mathrm{Al}$ powder used for the mixture. It is therefore speculated that the doped $\mathrm{Al}$ might have preferentially purged oxygen existing as oxides on metal surfaces. With the presence of $\mathrm{Si}$, the reduced metal likely reacts with $\mathrm{Si}$ immediately to form binary silicides. Hence the possible reactions should include the reduction by Al first, followed by immediate reaction with $\mathrm{Si}$, as shown below:

$$
2 \mathrm{Al}+1.5 \mathrm{TiO}_{2}+3 \mathrm{Si}=\mathrm{Al}_{2} \mathrm{O}_{3}+1.5 \mathrm{TiSi}_{2}
$$




$$
\begin{aligned}
& 2 \mathrm{Al}+1.5 \mathrm{ZrO}_{2}+3 \mathrm{Si}=\mathrm{Al}_{2} \mathrm{O}_{3}+1.5 \mathrm{ZrSi}_{2} \\
& 2 \mathrm{Al}+0.6 \mathrm{Nb}_{2} \mathrm{O}_{5}+2.4 \mathrm{Si}=\mathrm{Al}_{2} \mathrm{O}_{3}+1.2 \mathrm{NbSi}_{2} \\
& 2 \mathrm{Al}+1.5 \mathrm{MoO}_{2}+3 \mathrm{Si}=\mathrm{Al}_{2} \mathrm{O}_{3}+1.5 \mathrm{MoSi}_{2} \\
& 2 \mathrm{Al}+\mathrm{WO}_{3}+2 \mathrm{Si}=\mathrm{Al}_{2} \mathrm{O}_{3}+\mathrm{WSi}_{2}
\end{aligned}
$$

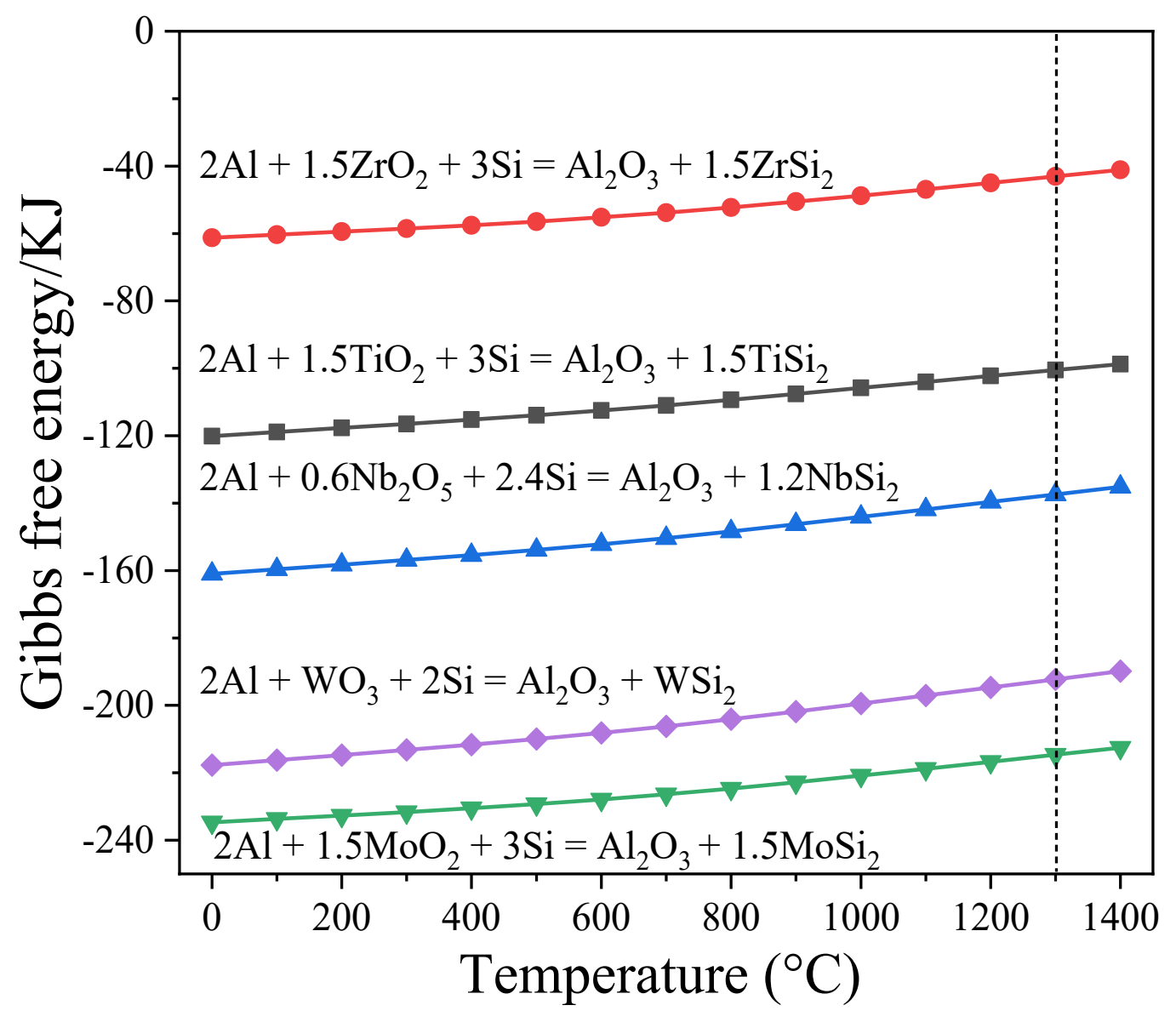

Fig. 4. Calculated Gibbs free energy of the possible reactions between aluminium and oxides existing on surface of metal raw materials, followed by reaction with $\mathrm{Si}$. The dashed line indicates the sintering temperature of $1300{ }^{\circ} \mathrm{C}$.

The Gibbs free energy for reaction (1)-(5) is estimated against reaction temperature, as illustrated in Fig. 4. The diagram does show that all reactions from (1) to (5) can happen before the sintering temperature of $1300^{\circ} \mathrm{C}$. The reduction of zirconia by aluminium followed by reaction with $\mathrm{Si}$ has negative $\Delta \mathrm{G}$, but much closer to 0 than other reactions, making $\mathrm{ZrO}_{2}$ more difficult to be reduced than other possible oxides in this formulation. 
It is noted from the possible reaction (1)-(5), the reduction of oxides leads to the formation of a range of binary silicides. Apart from some $\mathrm{ZrSi}_{2}$, all others likely react further to form HES compounds as no such binary compounds were detected by X-ray diffraction or chemical element mapping.

It seems that kinetics for these reactions were fast enough to complete under the current synthesis conditions because no other secondary phase is evidenced by XRD or chemical element mapping. The variation of shrinkage rate during SPS may also imply what might have happened during sintering. Fig. 5(a) and (b) show the recorded displacement and shrinkage rate respectively during synthesis and sintering of the HECs with and without Al doping in the same HES formulation. The peaks shown on the shrinkage rate curves are linked to the change of shrinkage rate by densification through sintering dictated by lattice diffusioncontrolled mass transportation, and/or through possible chemical reactions controlled new compound development. The appearance of multiple peaks evidences that multiple reactions happened. When the temperature reached $1300{ }^{\circ} \mathrm{C}$, further increase of time did not lead to the formation of more peaks (the 3 tiny peaks are deemed as artifacts), indicating that all possible reactions had completed inside a short period of time at or below $1300{ }^{\circ} \mathrm{C}$. The displacement curve for both HES reached the same level, indicating nearly same densities were achieved.

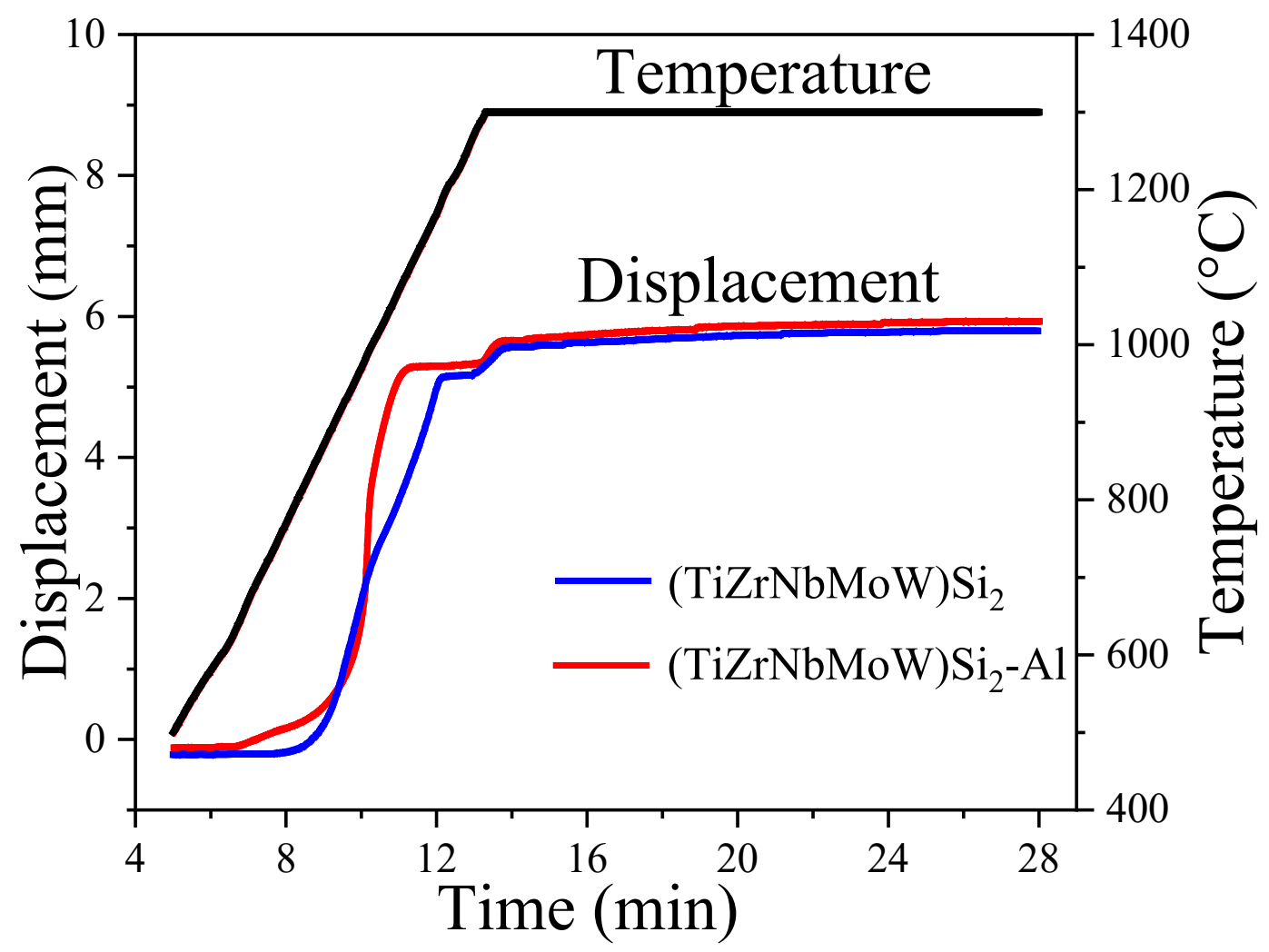


(a)

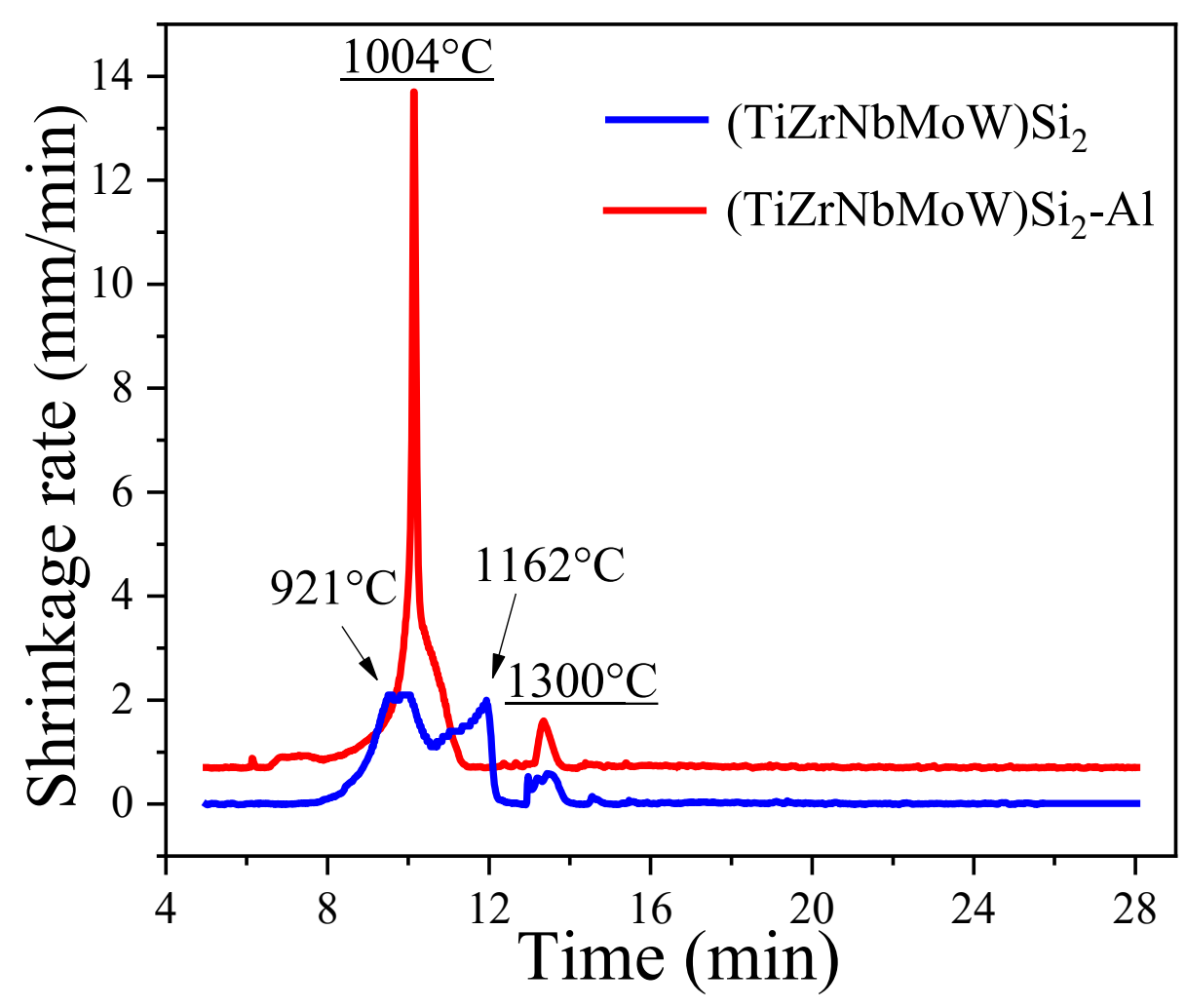

(b)

Fig. 5. (a) Recorded displacement and (b) shrinkage rate during SPS sintering for the HES with and without $\mathrm{Al}$ doping.

\subsection{Crystalline structure and DFT calculations}

A representative $\mathrm{XRD}$ spectrum of the as-synthesized material with and without Al doping is presented in Fig. 3(a) and (b) respectively.

In Fig 3(a), the diffraction peaks of $\mathrm{LaB}_{6}$ were marked as reference for calibrating peak positions. There are two sets of x-ray diffraction spectrum in the materials with Al doping, representing two different crystalline structures. The primary phase should be the high-entropy phase, showing clear hexagonal close-packed structure with a space group $\mathrm{P}_{2} 22$ by matching with diffraction data of ( $\left.\mathrm{Ti}_{0.6} \mathrm{~W}_{0.4}\right) \mathrm{Si}_{2}$ (JCPDS NO: 06-0599). The estimated lattice parameters of the hexagonal close-packed structure are $4.734 \AA$ for $a$ and $6.556 \AA$ for $c$. These experimental parameters will be compared with theoretically valculated ones later. 
The secondary phase $\mathrm{ZrSi}_{2}$ showed diffraction peaks that well match the data of JCPDS NO: 32-1499 with an orthorhombic C49 structure, giving lattice constant $a, b$ and $c$ a value of 3.69614 .751 and $3.665 \AA$, respectively. It is understandable that the diffraction peaks of $\mathrm{ZrSi}_{2}$ are significantly weaker than those of the primary phase because its quantity is quite small, though no credible method is available yet to quantify its fraction. These observations are consistent to the EDS chemical element maps of primary and secondary phases in these samples. No diffraction peaks of $\mathrm{Al}_{2} \mathrm{O}_{3}$ phase were found in the XRD spectra; this might be due to its poor crystallization at this relatively lower temperature, similar to the observation in previous research [40].

In Fig. 3(b), the primary XRD diffraction peaks of the material without $\mathrm{Al}$ doping match those in Fig 5(a) very well, evidencing the same HES with hexagonal crystal structure was produced. However, as secondary diffraction peaks, $\mathrm{ZrO}_{2}$ is found in Al-free HES, whereas $\mathrm{ZrSi}_{2}$ is detected in the Al-doped material (Note, the indexing of XRD spectrum in [22] overlooked the $\mathrm{ZrO}_{2}$ diffraction peaks at the time). The existence of zirconia is well supported by the EDS mapping in [22].

By now, XRD is the key experimental data for researchers to demonstrate if a high-entropy crystal is developed or not, but no XRD database is available yet in any established databases for supporting the XRD analysis without ambiguity. Any details on the related crystal structure and occupation of atoms in lattice are also not available. To validate the XRD analysis presented in this paper, we used density functional theory (DFT) to estimate the crystal structure and lattice parameters based on the chemical composition estimated from EDS data.

The DFT calculation shows that for a chemical composition as $\left(\mathrm{Ti}_{0.22} \mathrm{Zr}_{0.06} \mathrm{Nb}_{0.29} \mathrm{Mo}_{0.22}\right.$ $\left.\mathrm{W}_{0.21}\right) \mathrm{Si}_{2}$, the arrangements of the metallic elements (M) and silicon (S) are illustrated in Fig. 6a. The Si atoms stack in an $\mathrm{ABC}$ order, and the metallic atoms align to the middle point of each Si hexagon but sit in between two Si layers. The primitive cell structure is also presented in Fig. 6a. Calculation shows that a supercell composed of $2 \times 3 \times 1$ primitive cells can give an X-ray diffraction spectrum matching well with the experimental one. The calculated XRD spectrum is presented in Fig. 6b. All calculated diffraction peak positions fit nearly perfectly to those in experimentally measured spectrum. 


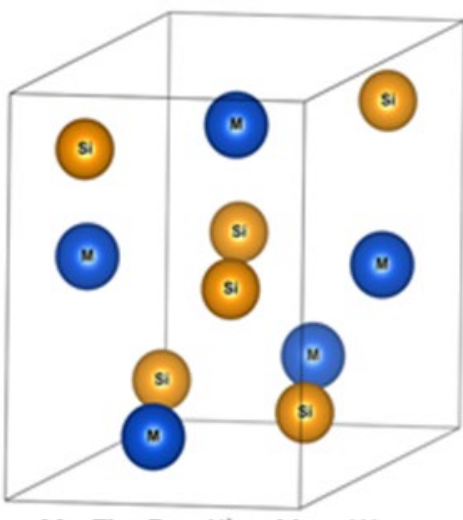

$\mathrm{M}=\mathrm{Ti}_{0.22} \mathrm{Zr}_{0.06} \mathrm{Nb}_{0.29} \mathrm{Mo}_{0.22} \mathrm{~W}_{0.20}$

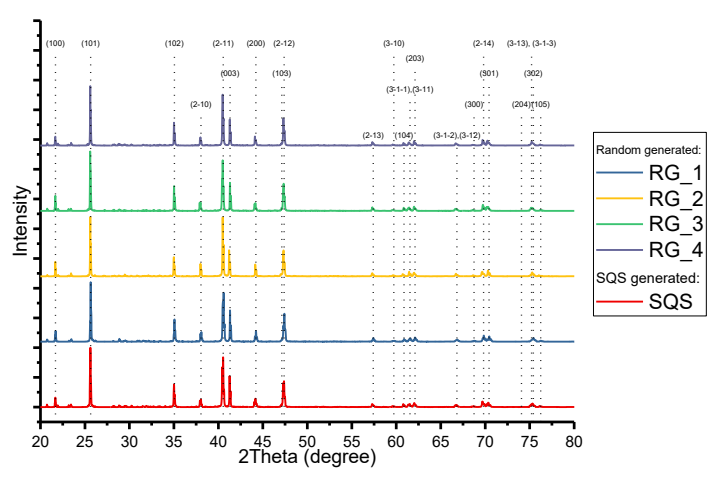

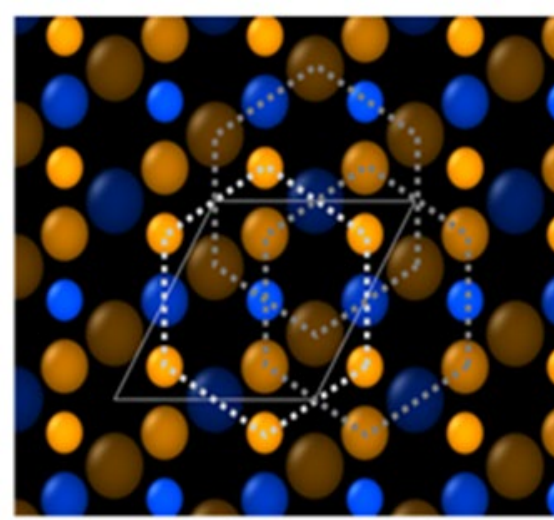

Layer $\quad \mathbf{M} \quad$ Si
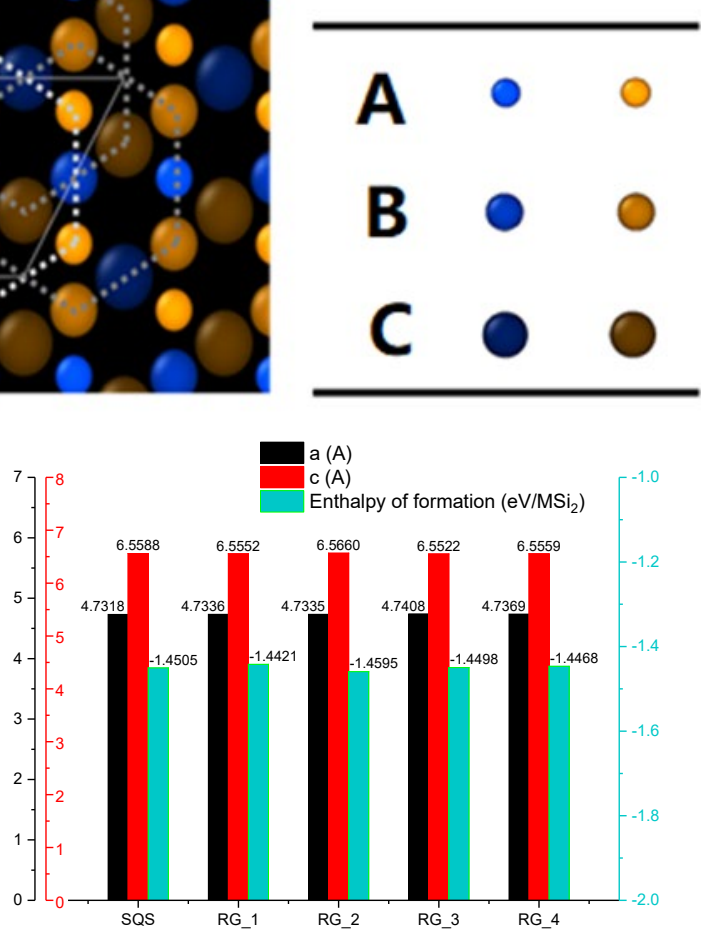

Fig. 6. Density functional theory (DFT) estimation based on the chemical composition from EDS data. (a) crystal structure and primitive cell of $\left(\mathrm{Ti}_{0.22} \mathrm{Zr}_{0.06} \mathrm{Nb}_{0.29} \mathrm{Mo}_{0.22} \mathrm{~W}_{0.2}\right) \mathrm{Si}_{2}$ predicted through DFT calculation; (b) calculated X-ray diffraction spectra based on a supercell of $2 \times 3 \times 1$ primitive cells, showing that diffraction peak positions well matched the experimental ones. Among the calculated spectra, the metallic elements were set in different positions, showing little changes of diffraction peak positions but limited change in relative intensity among the peaks; (c) calculated lattice parameters and enthalpy of formation of a HES crystal with cations randomly positioned in 5 different scenarios $S Q S$ and $R_{-}$1 to RG_4.

The $2 \times 3 \times 1$ supercell was generated by using a special quasirandom structure methodology [41,42] with ATAT [43], labelled as SQS. Given 5 different metallic elements exist in the supercell, we randomly chose 4 different positioning scenarios in lattice for these metallic atoms, labelled as RG_1 to $\mathrm{RG}_{-} 4$, and the corresponding diffraction spectra are included in Fig $6 \mathrm{~b}$ along with that for SQS. The results show that there is little variation for all diffraction peak positions, whilst there is a little variation in relative intensity of the diffraction peaks when the atomic positions are changed, which is expected due to the change of scattering factor for an atomic position in the lattice changed from one atom to another. The diffraction peak positions of HES are listed in Table 3 for comparison between those measured from experimental diffraction spectra and those from calculated spectra based on crystal structures predicted by DFT calculation. In general, at lower diffraction angles, i.e. lattice planes with 
larger distances, the measurements and calculated values have much better fitting, compared to those at higher diffraction angles.

\section{Table 3}

Comparison of X-ray diffraction peak position between measurements from experimental XRD spectra and calculated values based on a crystal structure predicted by DFT calculation.

\begin{tabular}{cccc}
\hline Diffraction peak & $\begin{array}{c}\text { Measurements } \\
\text { from experimental } \\
\text { XRD }\left(^{\circ}\right)\end{array}$ & $\begin{array}{c}\text { Calculated based a } \\
\text { crystal structure } \\
\text { predicted by DFT }\left(^{\circ}\right)\end{array}$ & $\begin{array}{c}\text { Difference } \\
\left({ }^{\circ}\right)\end{array}$ \\
\hline$(100)$ & 21.69 & 21.68 & $8.73 \mathrm{E}-03$ \\
$(101)$ & 25.64 & 25.63 & $9.40 \mathrm{E}-03$ \\
$(102)$ & 35.06 & 35.01 & $4.72 \mathrm{E}-02$ \\
$(2-10)$ & 38.05 & 38.04 & $2.59 \mathrm{E}-03$ \\
$(2-11)$ & 40.55 & 40.43 & $1.21 \mathrm{E}-01$ \\
$(003)$ & 41.31 & 41.26 & $4.86 \mathrm{E}-02$ \\
$(-200)$ & 44.22 & 44.15 & $6.87 \mathrm{E}-02$ \\
$(-201)$ & 46.44 & 46.37 & $7.14 \mathrm{E}-02$ \\
$(-103)$ & 47.13 & 47.07 & $5.96 \mathrm{E}-02$ \\
$(2-12)$ & 47.40 & 47.37 & $2.86 \mathrm{E}-02$ \\
$(-202)$ & 52.69 & 52.62 & $7.48 \mathrm{E}-02$ \\
$(2-13)$ & 57.41 & 57.29 & $1.20 \mathrm{E}-01$ \\
$(3-10)$ & 59.72 & 59.54 & $1.84 \mathrm{E}-01$ \\
$(-104)$ & 60.87 & 60.79 & $7.96 \mathrm{E}-02$ \\
$(3-11)$ & 61.54 & 61.53 & $7.49 \mathrm{E}-03$ \\
$(-203)$ & 62.10 & 62.01 & $9.14 \mathrm{E}-02$ \\
$(3-1-2)$ & 66.82 & 66.78 & $3.62 \mathrm{E}-02$ \\
$(-300)$ & 68.74 & 68.63 & $1.16 \mathrm{E}-01$ \\
$(2-14)$ & 69.81 & 69.72 & $9.25 \mathrm{E}-02$ \\
$(-301)$ & 70.43 & 70.31 & $1.19 \mathrm{E}-01$ \\
$(-204)$ & 74.08 & 73.97 & $1.10 \mathrm{E}-01$ \\
$(3-13)$ & 75.20 & 75.03 & $1.71 \mathrm{E}-01$ \\
$(-302)$ & 75.41 & 75.28 & $1.25 \mathrm{E}-01$ \\
$(-105)$ & 76.23 & 76.10 & $1.36 \mathrm{E}-01$ \\
\hline & & &
\end{tabular}




\section{Table 4}

Calculated DFT structure and results.

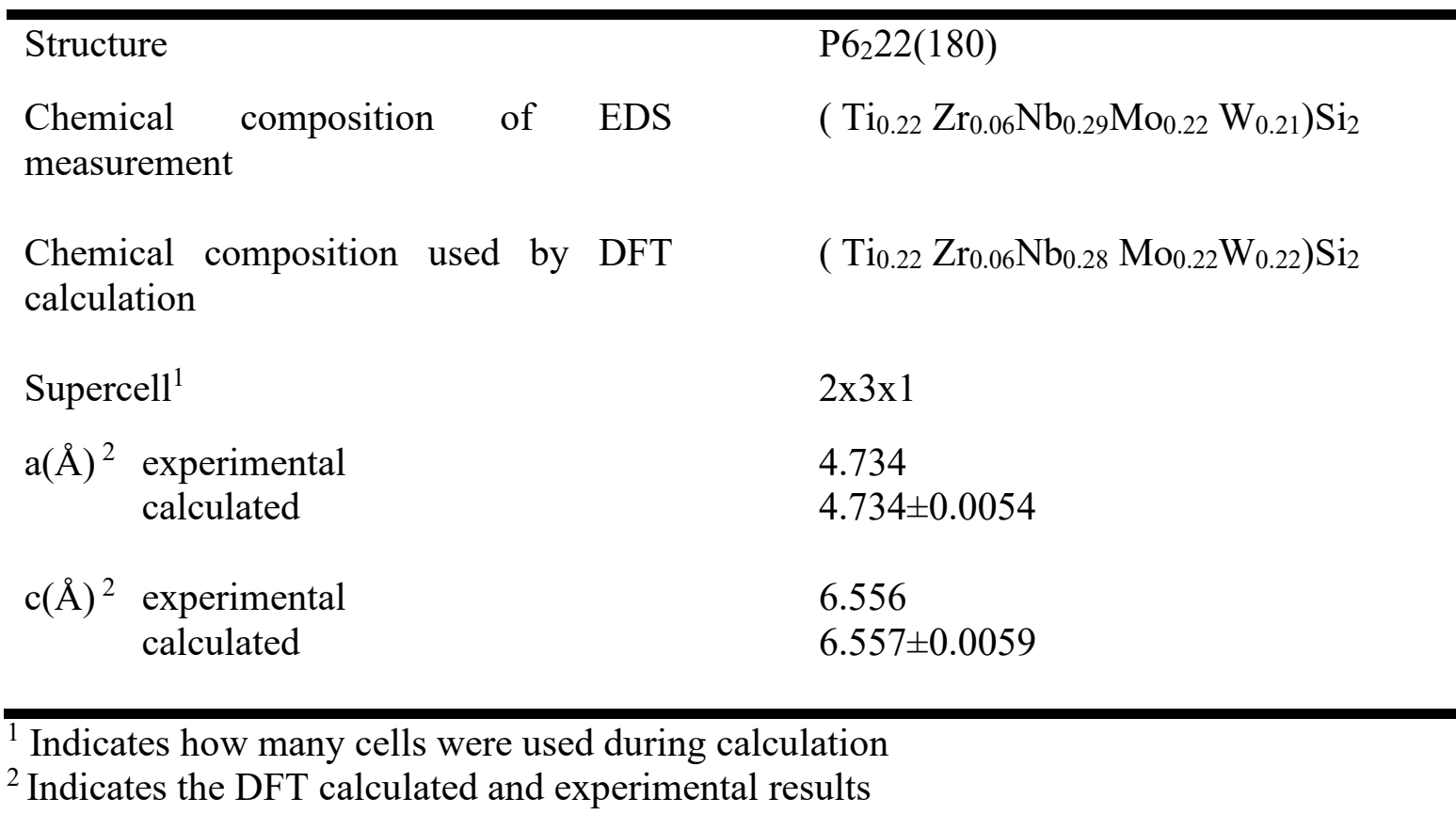

Based on the supercell, the lattice parameters are estimated for all 5 scenarios of positions of metallic atoms. The results are summarised in Table 4. The calculated values for a and c have little difference, compared to the experimentally measured values.

Another aim of setting 5 random position scenarios for metallic elements is to evaluate if the enthalpy of formation of the crystal has any sensible changes. The results are illustrated in Fig.6c, showing the minimum enthalpy of formation is -1.445 and the maximum one -1.459 with an average of $-1.449 \pm 0.0056 \mathrm{eV}$ per molecule $\mathrm{MSi}_{2}$ where $\mathrm{M}$ represent $\left(\mathrm{Ti}_{0.22} \mathrm{Zr}_{0.06} \mathrm{Nb}_{0.28}\right.$ $\mathrm{Mo}_{0.22} \mathrm{~W}_{0.22}$ ). This very little change in the enthalpy of formation implies that the metallic elements in a HES can be positioned randomly without changing structural nature of the crystal, the one that a high entropy material is supposed to have [1].

\subsection{Hardness}

The Vickers hardness $(\mathrm{Hv})$ of the as-manufactured HES ceramics was measured and compared. The average hardness was $13.58( \pm 0.6) \mathrm{GPa}$ for the HES ceramic with aluminum doping. There is a clear mild increase in hardness, compared to a HES ceramic processed without aluminum doping, which was $12.09( \pm 0.5) \mathrm{GPa}$. We believe that the mild increase of 
hardness may be a result of harder particles of alumina dispersed in the microstructure as shown in Fig. 1, which can restrain possible intergranular fracture and lattice slips, as observed in other ceramics $[44,45]$.

\section{Conclusions}

This study led to the following conclusions:

a) A high entropy disilicide ceramic was successfully developed in the (TiZrNbMoW)Si 2 system in presence of aluminium doping. All cations were roughly in equimolar content (22-29 mol\%), except for $\mathrm{Zr}$, which was present in only $6 \mathrm{~mol} \%$. In agreement, no other HES crystal phases were detected apart from secondary compounds, $\mathrm{Al}_{2} \mathrm{O}_{3}$ and $\mathrm{ZrSi}_{2}$. This Al-doped HES ceramic gave a Vicker's hardness of $13.58 \mathrm{GPa}$, slightly higher than Al-free HES, owing to the formation of scattered $\mathrm{Al}_{2} \mathrm{O}_{3}$ hard particles scattered throughout the microstructure.

b) Aluminium was preferentially oxidised into $\mathrm{Al}_{2} \mathrm{O}_{3}$ by directly reacting with gaseous oxygen or reducing oxides existing on the surfaces of metal particles. Only about $\sim 1 / 3$ of zirconium participated to the development of HES, and the rest of zirconium reacted with silicon to form $\mathrm{ZrSi}_{2}$ crystallites

c) Through DFT and X-ray diffraction simulation, a 2x3x1 supercell of a hexagonal closepacked crystal structure was proposed. The calculated X-ray diffraction pattern of this supercell matches well with the experimental diffraction pattern of the as-developed HES.

d) Supported by DFT calculation, analysis shows that the 5 metallic elements likely have no preferential occupation at the cation positions in a HCP structure of the assynthesized HES compound. 


\section{Acknowledgement}

This work was supported by National Natural Science Funds (No. 51873103, 51532009). Capacity Building Project of Some Local Colleges and Universities in Shanghai (No.17030501200), Talent Program of Shanghai University of Engineering Science (No.2017RC422017), and First-rate Discipline Construction of Applied Chemistry (No. 2018xk-B-06). The Loughborough researchers are grateful for having support from various research projects associated and the University.

\section{Reference}

[1] J.W. Yeh, S.K. Chen, S.J. Lin, J.Y. Gan, T.S. Chin, T.T. Shun, C.H. Tsau, S.Y. Chang, Nanostructured High-Entropy Alloys with Multiple Principal Elements: Novel Alloy Design Concepts and Outcomes, Adv. Eng. Mater. 6 (5) (2004) 299-303.

[2] Y. Zhang, T.T. Zuo, Z. Tang, M.C. Gao, K.A. Dahmen, P.K. Liaw, Z.P. Lu, Microstructures and properties of high-entropy alloys, Prog. Mater. Sci. 61 (2014) 1-93.

[3] D.B. Miracle, O.N. Senkov, A critical review of high entropy alloys and related concepts, Acta Mater. 122 (2017) 448-511.

[4] B. Gludovatz, A. Hohenwarter, D. Catoor, E.H. Chang, E.P. George, R.O. Ritchie, A fracture-resistant high-entropy alloy for cryogenic applications, Science. 345 (6201) (2014) 1153-1158.

[5] C.M. Rost, E. Sachet, T. Borman, A. Moballegh, E.C. Dickey, D. Hou, J.L. Jones, S. Curtarolo, J.P. Maria, Entropy-stabilized oxides, Nat. Commun. 6 (2015) 8485.

[6] H. Chen, H.M. Xiang, F.Z. Dai, J.C. Liu, Y.C. Zhou, High entropy $\left(\mathrm{Yb}_{0.25} \mathrm{Y}_{0.25} \mathrm{Lu}_{0}\right.$ $\left.{ }_{25} \mathrm{Er}_{0.25}\right)_{2} \mathrm{SiO}_{5}$ with strong anisotropy in thermal expansion, J. Mater. Sci. Technol.36 (1) (2019) 134-139.

[7] F. Li, L. Zhou, J.X. Liu, Y.C. Liang, G.J. Zhang, High entropy pyrochlores with low thermal conductivity for thermal barrier coating materials, J. Adv. Ceram 8 (4) (2019) 576-582.

[8] K. Chen, X. Pei, L. Tang, H. Cheng, Z. Li, C. Li, X. Zhang, L. An, A five-component entropy-stabilized fluorite oxide, J. Eur. Ceram. Soc. 38 (2018) 4161-4164.

[9] S. Jiang, T. Hu, J. Gild, N. Zhou, J. Nie, M. Qin, T. Harrington, K. Vecchio, J. Luo, A new class of high-entropy perovskite oxides, Scr. Mater. 142 (2018) 116-120.

[10] Y. Dong, K. Ren, Y.H. Lu, Q.K. Wang, J. Liu, Y.G. Wang, High-entropy environmental barrier coating for the ceramic matrix composites, J. Eur. Ceram. Soc. 39 (2019) 2574-2579.

[11] F. Li, Y. Lu, X.G. Wang, W.C. Bao, J.X. Liu, F.F. Xu, G.J. Zhang, Liquid precursorderived high-entropy carbide nanopowders, Ceram. Int. 45 (2019) 22437-22441.

[12] E. Castle, T. Csanádi, S. Grasso, J. Dusza, M. Reece, Processing and Properties of HighEntropy Ultra-High Temperature Carbides, Sci. Rep. 8 (1) (2018) 8609.

[13] B.L. Ye, T.Q. Wen, K.H. Huang, C.Z. Wang, Y.H. Chu, First-principles study, fabrication, and characterization of $\left(\mathrm{Hf}_{0.2} \mathrm{Zr}_{0.2} \mathrm{Ta}_{0.2} \mathrm{Nb}_{0.2} \mathrm{Ti}_{0.2}\right) \mathrm{C}$ high-entropy ceramic, J. Am. Ceram. Soc. 102 (2019) 4344-4352 
[14] X. Yan, L. Constantin, Y. Lu, J.F. Silvain, M. Nastasi, C. Bai, $\left(\mathrm{Hf}_{0.2} \mathrm{Zr}_{0.2} \mathrm{Ta}_{0.2} \mathrm{Nb}_{0.2} \mathrm{Ti}_{0.2}\right) \mathrm{C}$ high-entropy ceramics with low thermal conductivity, J. Am. Ceram. Soc. 101 (2018) 44864491.

[15] X.F. Wei, J.X. Liu, F. Li, Y. Qin, Y.C. Liang, G.J. Zhang, High entropy carbide ceramics from different starting materials, J. Eur. Ceram. Soc. 39 (10) (2019) 2989-2994.

[16] X. F. Wei, Y. Qin, J. X. Liu, F. Li, Y. C. Liang, G. J. Zhang, Gradient microstructure development and grain growth inhibition in high-entropy carbide ceramics prepared by reactive spark plasma sintering, J. Eur. Ceram. Soc. 40 (4) (2020) 935-941.

[17] X.Q. Shen, J.X. Liu, F. Li, G.J. Zhang, Preparation and characterization of diboride-based high entropy $\left(\mathrm{Ti}_{0.2} \mathrm{Zr}_{0.2} \mathrm{Hf}_{0.2} \mathrm{Nb}_{0.2} \mathrm{Ta}_{0.2}\right) \mathrm{B}_{2}$-SiC particulate composites, Ceram. Int. 45 (2019) 24508-24514.

[18] J.F. Gu, J. Zou, S.K. Sun, H. Wang, S.Y. Yu, J.Y. Zhang, W.M. Wang, Z.Y. Fu, Dense and pure high-entropy metal diboride ceramics sintered from self-synthesized powders via boro/carbothermal reduction approach, Sci. China. Mater. (2019) 1-12.

[19] J. Gild, Y. Zhang, T. Harrington, S. Jiang, T. Hu, M.C. Quinn, W.M. Mellor, N. Zhou, K. Vecchio, J. Luo, High-Entropy Metal Diborides: A New Class of High-Entropy Materials and a New Type of Ultrahigh Temperature Ceramics, Sci. Rep. 6 (2016) 37946.

[20] Y. Zhang, W.M. Guo, Z.B. Jiang, Q.Q. Zhu, S.K. Sun, Y. You, K. Plucknett, H.T. Lin, Dense high-entropy boride ceramics with ultra-high hardness, Scr. Mater. 164 (2019) 135-139. [21] F. Li, W.C. Bao, S. K. Sun, L. Zhou , J. X. Liu , F.F. Xu , G.J. Zhang, Synthesis of singlephase metal oxycarbonitride ceramics, Scr. Mater. 176 (2020) 17-22.

[22] Y. Qin, J.X. Liu, F. Li, X.F. Wei, H.Z. Wu, G.J. Zhang, A high entropy silicide by reactive spark plasma sintering, J. Adv. Ceram. 8 (1) (2019) 148-152.

[23] W.G. Fahrenholtz, G.E. Hilmas, S.C. Zhang, S. Zhu, Pressureless Sintering of Zirconium Diboride: Particle Size and Additive Effects, J. Am. Ceram. Soc. 91 (2010) 1398-1404.

[24] J. Zou, G.J. Zhang, S.K. Sun, H.T. Liu, Y.M. Kan, J.X. Liu, C.M. Xu, $\mathrm{ZrO}_{2}$ removing reactions of Groups IV-VI transition metal carbides in $\mathrm{ZrB}_{2}$ based composites, J. Eur. Ceram. Soc. 31 (3) (2011) 421-427.

[25] H.B. Ma, J. Zou, P. Lu, J.T. Zhu, Z.Q. Fu, F.F. Xu, G.J. Zhang, Oxygen contamination on the surface of $Z_{r B}$ powders and its removal, Scr. Mater. 127 (2017) 160-164.

[26] J. Gild, J. Braun, K. Kaufmann, E. Marin, T. Harrington, P. Hopkins, K. Vecchio, J. Luo, A high-entropy silicide: $\left(\mathrm{Mo}_{0.2} \mathrm{Nb}_{0.2} \mathrm{Ta}_{0.2} \mathrm{Ti}_{0.2} \mathrm{~W}_{0.2}\right) \mathrm{Si}_{2}$, J. Mater. 5 (2019) 337-343.

[27] F. L. Riley, Silicon nitride and related materials, J. Am. Ceram. Soc. 83 (2) (2000) 24565.

[28] H. Yokota, M. Ibukiyama, Effect of lattice impurities on the thermal conductivity of $\beta$ $\mathrm{Si}_{3} \mathrm{~N}_{4}$, J. Eur. Ceram. Soc. 23 (1) (2003) 55-60.

[29] M. Kitayama, K. Hirao, A. Tsuge, K. Watari, S. Kanzaki, Thermal Conductivity of $\beta$ $\mathrm{Si}_{3} \mathrm{~N}_{4}$ : II, Effect of Lattice Oxygen, J. Am. Ceram. Soc. 83 (8) (2010) 1985-1992.

[30] J. Zou, G.J. Zhang, J. Vleugels, O.V.D. Biest, High temperature strength of hot pressed $\mathrm{ZrB}_{2}-20 \mathrm{vol} \% \mathrm{SiC}$ ceramics based on $\mathrm{ZrB}_{2}$ starting powders prepared by different carbo/borothermal reduction routes, J. Eur. Ceram. Soc. 33 (10) (2013) 1609-1614.

[31] H.B. Ma, Z.Y. Man, J.X. Liu, F.F. Xu, G.J. Zhang, Microstructures, solid solution formation and high-temperature mechanical properties of $\mathrm{ZrB}_{2}$ ceramics doped with 5 vol.\% WC, Mater. Design. 81 (2015) 133-140.

[32] S.C. Zhang, G.E. Hilmas, W.G. Fahrenholtz, Pressureless Densification of Zirconium Diboride with Boron Carbide Additions, J. Am. Ceram. Soc. 89 (5) (2006) 1544-1550.

[33] P. Giannozzi, S. Baroni, N. Bonini, M. Calandra, R. Car, C. Cavazzoni, D. Ceresoli, G.L. Chiarotti, M. Cococcioni, I. Dabo, QUANTUM ESPRESSO: a modular and open-source software project for quantum simulations of materials, Journal of physics: Condensed matter 21(39) (2009) 395502. 
[34] P. Giannozzi, O. Andreussi, T. Brumme, O. Bunau, M.B. Nardelli, M. Calandra, R. Car, C. Cavazzoni, D. Ceresoli, M. Cococcioni, Advanced capabilities for materials modelling with Quantum ESPRESSO, Journal of Physics: Condensed Matter 29(46) (2017) 465901.

[35] J.P. Perdew, A. Ruzsinszky, G.I. Csonka, O.A. Vydrov, G.E. Scuseria, L.A. Constantin, $\mathrm{X}$. Zhou, K. Burke, Restoring the density-gradient expansion for exchange in solids and surfaces, Physical review letters 100(13) (2008) 136406.

[36] A. Zunger, S.H. Wei, L. Ferreira, J.E. Bernard, Special quasirandom structures, Physical Review Letters 65(3) (1990) 353.

[37] A. Van de Walle, P. Tiwary, M. De Jong, D. Olmsted, M. Asta, A. Dick, D. Shin, Y. Wang, L.-Q. Chen, Z.-K. Liu, Efficient stochastic generation of special quasirandom structures, Calphad 42 (2013) 13-18.

[38] A. Kokalj, XCrySDen - a new program for displaying crystalline structures and electron densities, Journal of Molecular Graphics and Modelling 17(3-4) (1999) 176-179.

[39] K. Momma, F. Izumi, VESTA 3 for three-dimensional visualization of crystal, volumetric and morphology data, J. Appl. Cryst. 44 (6) (2011) 1272-1276.

[40] G.J. Zhang, X.M. Yue, T. Watanabe, Synthesis of $\mathrm{Mo}(\mathrm{Si}, \mathrm{Al})_{2}$ alloy by reactive hot pressing at low temperatures for a short time, J. Mater. Sci. 34 (3) (1999) 593-597.

[41] A. Zunger, S.H. Wei, L. Ferreira, J.E. Bernard, Special quasirandom structures, Phys. Rev. Lett. 65 (1990) 353-356.

[42] A. Van de Walle, P. Tiwary, M. De Jong, D. Olmsted, M. Asta, A. Dick, D. Shin, Y. Wang, L.Q. Chen, Z.K. Liu, Efficient stochastic generation of special quasirandom structures, Calphad. 42 (2013) 13-18.

[43] A. Van De Walle, M. Asta, G. Ceder, The alloy theoretic automated toolkit: A user guide, Calphad. 26 (2002) 539-553.

[44] H. Wu, Understanding residual stresses and fracture toughness in ceramic nanocomposites-10, in Residual Stresses in Composite Materials, in: M.M. Shokrieh (Ed.), Woodhead Publishing, (2014) 256-292.

[45] H. Wu, S. Roberts, B. Derby, Ductile deformation in alumina/silicon carbide nanocomposites, Nanostructured Materials and Nanotechnology III. John Wiley \& Sons, Inc. (2009) 155-164. 